\title{
A Study of Geomagnetic Effects Associated with Auroral Zone Electron Precipitation Observed by Balloons
}

\author{
By W.H. CAMPBELL \\ Central Radio Propagation Laboratory Boulder Laboratories National \\ Bureau of Standards, Boulder, Colorado, U.S.A.
}

(Received : December 10, 1963)

\begin{abstract}
Magnetograms and geomagnetic micropulsation data were reviewed for fifteen bremsstrahlung $X$-ray events detected by balloon borne counters at College, Alaska, from 1960 to 1962 . Derived total disturbance field variations and line current electrojet triangulations were of value in interpreting the magnetic field effects associated with the particle precipitation. The micropulsations and rapid fluctuations in auroral zone bays are thought to have their source in the enhanced conductivity created by and local to the particle precipitation.
\end{abstract}

\section{Introduction}

The purpose of this paper is to investigate the surface measurements of the variations in the total magnetic field, the ionospheric current, and the geomagnetic micropulsations associated with electron precipitation in the auroral zone. The available records from balloon flights at College, Alaska, in the years 1960 to 1962 were collected without regard to size of events. From this group, the times selected for analysis were those in which College magnetograms and micropulsation records were also obtainable. The observations presented here are for fifteen occasions which sample periods of extreme activity and quiet. The study hopes to show that an analysis of the auroral zone magnetic records can augment the interpretation of the bremsstrahlung data from balloons and aid in the general evaluation of electron precipitation size and location. The data imply that often a large part of the auroral electrojet variation may be explained by conductivity fluctuations rather than changes in the driving electric field.

First, let us briefly recall what has been published relating the bombarding electrons to the magnetic field variations in the high latitudes. The existence of a connection between the visual aurora and magnetic activity was known for a great many years (Burritt, 1845). Recently, Davis (1962) analyzed all sky photographs in Alaska for the I.G.Y. and related motions of auroral forms with the magnetic field variations. A major portion of the auroral luminosity has been attributed to low energy bombarding electrons (Ohmholt, 1959). Direct measurements by rockets actually flown within the emitting region indeed indicated that much of the auroral light was produced by electrons with energies less that $10 \mathrm{kev}$ (Davis, Berg, and Meredith, 1960; McIlwain, 1960). Balloon borne X-ray counters measuring the 
bremsstrahlung from the precipitating electrons have obtained temporal variations in the flux which were generally related to disturbances in ionospheric absorption, auroral intensity, and magnetic field variations (Anderson, 1958, 1960 ; Anderson and DeWitt, 1963; Anderson and Enemark, 1960; Brown, 1961; Brown et al, 1961; Pfotzer et al, 1962; and Winckler et al, 1958, 1959, 1962). The auroral zone electron influx has even been observed by satellites (O'Brien and Laughlin, 1962; and Maehlum and O'Brien, 1963). In a study of geomagnetic sudden commencements and sudden impulses Matsushita $(1961,1962)$ concluded that there were usually associated increases of ionization resulting from an influx of charged particles from outside the earth's atmosphere. In 1961 it was suggested that by using the magnetic data to triangulate to the auroral electrojet the magnitude and time differences in ionospheric absorption, bremsstrahlung count rate and geomagnetic field could be explained; that is, the location and size variation of both the electrojet current and the electron precipitation region were intimately related (Campbell, 1962a; Campbell and Matsushita, 1962). Subsequent studies by Brown and Campbell (1962), Barcus and Brown (1962) and Brown (1962) encouraged the further use of position-motion effects together with the flux variations to explain the relationship of magnetic bays to the bremsstrahlung count rates. The present paper will attempt to evaluate this method.

Observations of geomagnetic micropulsations in the auroral zones are dominated by a class of events with field components spread throughout the frequency range of $2 \mathrm{c} / \mathrm{s}$ to $0.005 \mathrm{c} / \mathrm{s}$. From a study of the pulsations, associated auroral absorption (Campbell and Leinbach, 1961) and auroral luminosity (Campbell and Rees, 1961) it was concluded that variations in the number of incoming electrons could best explain the related data. Troitskaya (1961) noticed that when the magnetic field is disturbed intense bursts of cosmic rays in the stratosphere coincide with the excitation of irregular micropulsations. Examples of micropulsation and bremsstrahlung events occurring simultaneously have been published (Campbell, 1961). Short period bunching and pulsation of the incoming electrons was reported by most balloon observers (Pfotzer et al., 1962; Winckler, Bhavsar and Anderson, 1962; Anger et al., 1963). From a measurement of the energy spectrum, Evans (1963) concluded that the peaks of intensity of his observed pulsating auroral zone $X$-ray event were attributed to variations in the flux of electrons on the atmosphere; horizontal motion of the precipitation region past the sensor window was considered to be quite slow in contrast. It had been postulated that with the arrival of a solar terrestrial disturbance front at the outer magnetospheric boundary the pitch angles of newly trapped particles are peroiodically redistributed; this modulates the precipitation of these particles into the earth's atmosphere and, in turn, sets up irregular variations of the ionospheric current system (Campbell and Matsushita, 1962; Campbell, 1962a). An older theory that geomagnetic pulsations are caused by fluctuations of the $S q$ current system (Terada, 1917) was remodeled, and it was proposed that some types of magnetic field fluctuations arise when a varying patch of ionospheric conductivity, caused by the particle bombardment, leads to a slight change in the current pattern of the auroral electrojet (Campbell, 1962b). The present paper will exhibit the relationship of geomagnetic micropulsations to the electron precipitation and the ionospheric current. 


\section{The Data}

The data used in this study are count rate fluctuations in electron bremsstrahlung obtained at balloon altitudes, standard observatory magnetograms and induction loop geomagnetic micropulsation records. The fifteen balloon events that determined the data groups reported here cover a total of 80 hours which show an extreme range of activity. The general summertime flight schedule accounted for the selection of seven events in June, six in July, and only one each in March and August. The schedule of near midnight launchings and the usual, less than 24 hour, flight duration caused a post-midnight sample pattern (Fig. 1).

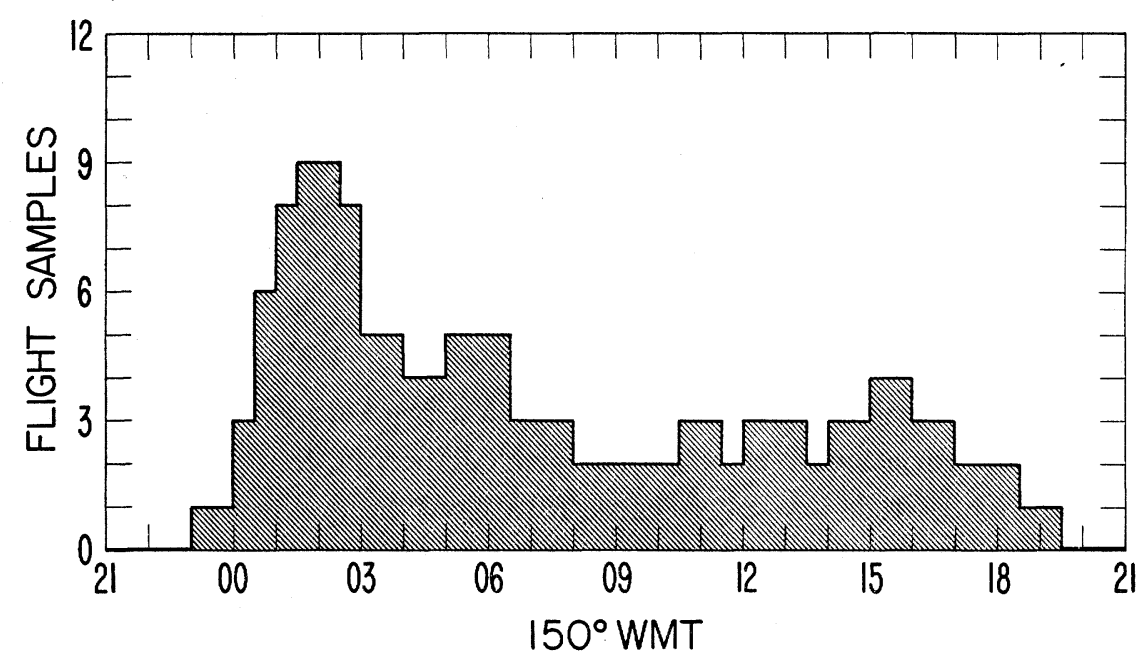

Fig. 1. Half-hour data samples for the fifteen balloon flights near College, Alaska, from 1960 to 1962 .

It is difficult to obtain a straightforward analytic resume of the concurrent phenomena from a simple overlay of the records because of the complex manner in which these records are related to the physical processes. Let us, then, review some characteristics of the data which may aid our interpretation.

\section{1. Balloon $X$-ray counters}

The times at which certain prescribed total photon counts from $X$-ray sensors carried aloft by balloons are telemetered to ground stations and recorded as an activity count rate. The events obtained from either geiger or scintillation counters have not been separated in this report, even though the photon counting efficiency differs on the two systems, because the absolute flux was not of particular importance in this present study.

An accurate evaluation of the scattering and absorption of the bremsstrahlung photons is difficult and depends upon the amount and constitution of atmosphere between the balloon and the emission height. The ceiling for the flights was limited to about $32 \mathrm{~km}$. The helium balloons constantly drift and lose altitude for 10 or 20 hours until at about $25 \mathrm{~km}$, with the present day counters, there is generally too much atmosphere above the sensor to permit detection of even a modestly active event. The cone of acceptance or "bremsstrah. 
lung window" closes in with decreasing altitude of the detector and consequently there is a decrease in area of the ionospheric region where electron precipitation may be detected. The loss of altitude by the balloon is generally gradual enough, though, to accurately compare the precipitation over several hours in any one flight. A true estimate of the flux would require a knowledge of the angular distribution of incident electrons within the source region, thus it will not be attempted in this paper.

The counters, which are limited in photon energy detection to the range from about 20 kev to several hundred kev, certainly indicate a similar electron energy; however, the atmosphere's ionization and emission crossections maximize near 30 to 200 electron volts. As a consequence, slight changes in the measured flux-energy profile in the kev region may be associated with a rather large ionization and luminosity changes.

The drift of the balloon with respect to the region of precipitation is recorded as a time change in the flux and a softening or hardening of the photon spectrum. The balloon generally moves slowly, however, so the fluctuation in count rate will be considered primarily as changes in quantity or position of the electron precipitation. In the following figures the photon count rate above an estimated cosmic ray background level will be presented and we will interest ourselves only in the relative variations over a period of several hours.

\section{2. Magnetograms and the total field}

Many ionospheric phenomena have been related to the auroral zone magnetic disturbances through the variation of the magnetic north component, $H$. The east-west electrojet currents in the high latitude ionosphere cause $H$ to have the greatest departure from the quiet day variation of the three field vectors and thereby determine the auroral zone $K$ and $Q$ indices. One question to be asked in this paper is whether the inclusion of the variation of the other components, $D$ and $Z$ (east and down) adds anything to our understanding of the relationship of magnetic fields to the electron precipitation.

The magnitude of the vector sum of the three orthogonal field vectors (upon subtraction of the quiet day variations), which may be called the total variation field, " $F$ ", is presented for each event in this paper. Should an electrojet be essentially a nearby sheet current more than several hundred kilometers broad or should it be composed of closely spaced multiple line currents whose intensity vary rather independently, the magnitude of the total variation field, $F$, rather than a representation of the vector field by a simple line current would be more indicative of the electrojet changes.

\section{3. The current triangulation}

The orthogonal field vector variations obtained from the magnetometer scalings, after allowance for an induced current contribution, are used to determine the distance to an assumed line current source. This is the distance between the observing station on the ground and the interesection of a perpendicular to the total disturbance variation field vector with a $100 \mathrm{~km}$ plane in the ionospheric $E$-region. The history of such a line current is presented in three time plots. I (amperes) represents the amplitude variation of an infinitely long line current flowing at $100 \mathrm{~km} . S(\mathrm{~km})$ is the surface projection of the closest approach distance of this line current to the observatory; distances greater than $400 \mathrm{~km}$ are considered unreliable. $\theta$ indicates the direction in which $S$ is measured in a geomagne- 
tic coordinate system; e.g., a (geomagnetic) westward electrojet would be indicated as a $\theta$ point in the north or south. When $\theta$ varies suddenly between $N$ and $S$ or $E$ and $W$, a change in region of the current is indicated which usually is interpreted as an overhead passing of of the electrojet.

A number of problems arise in any line current triangulation. The current certainly flows in the conducting foot of the ionosphere so the $100 \mathrm{~km} E$-region selection cannot be greatly in error; height variations within the sharp conductivity maximum (Baker and Martyn, 1953; and S. Chapman, 1956a) cannot appreciably affect the accuracy of the location. However, Chapman and Whitehead (1923) and Chapman (1935) indicated the necessity of compensating for induced currents within the earth when evaluating the ionospheric current system. For the quiet day variations, the true external field is usually obtained from two-thirds of the horizontal vectors and twice the vertical vector. From dual station triangulation of ionospheric sources one does obtain values close to these (Campbell and Matsushita, 1962) although other induced current correction factors have been suggested (Akasofu, 1960; Barcus and Brown, 1962; Marsh, 1963). If an improper adjustment is made, neither the direction of motion nor the time of overhead passing of the electrojet would be affected; the distance away, the rate of change of this distance, and the current magnitude as a function of distance would all be somewhat in error.

The infinite line approximation becomes quite poor for an extended sheet or multiple element current and for systems which deviate greatly from a straight line in less than several hundred kilometers of length.

A location determination also depends upon a precise evaluation of the electrojet's contribution to the measured field intensity. The month's average "quiet day field" is usually considered to be the base line from which a disturbed field is measured. Magnetic storm variations in progress during the bay events (Chapman, 1956b) were not taken into account in the present paper since the auroral zone disturbances on the magnetic records are dominated by the proximity of ionospheric current. Nevertheless, outer magnetospheric changes will shift the "base line" for the bay measurements and thus vary the average location as well as the time of overhead passing of the triangulated current. It is hoped that such slow changes will not noticeably alter the computed direction of motion on time scales less than one-half hour.

\section{4. Micropulsations}

The reported observations of rapid geomagnetic field fluctuations at a College station near the balloon launching site were detected with various 2 meter diameter loop antennas of 16,000 to 32,000 turns with the axes located in the magnetic $N$-S direction. The received signal was compensated for the frequency dependence of the antenna, limited to a 5 to 30 sec. period band-pass and chart recorded. Scalings were made of the average peak to peak activity excursions in five minute intervals. Induced fields are thought to contribute less than $10 \%$ to the observed pulsations; no correction was made. The field vectors are principally in the $N$-S direction; the occasional activity differences in the surface orthogonal components usually disappear for the scaling interval taken. In the following figures the $N$-S micropulsation amplitudes may be considered to be a record of the total field fluctuation 
in the above frequency range. The micropulsation events associated with the particle flux in the high latitudes have been called "spread frequency" or "storm" events because of their relatively large amplitude, spectacular appearance with frequency components from $2 \mathrm{c} / \mathrm{s}$ to less than $0.005 \mathrm{c} / \mathrm{s}$. Occasionally a changing or single frequency may dominate the spectrum but there is no evidence that the regular oscillations in the $2 \mathrm{c} / \mathrm{s}$ to $0.2 \mathrm{c} / \mathrm{s}$ range (sometimes referred to as "pearls" because of their "beat" type aspect) have any relationship whatsoever to the particle precipitation measured by balloon $X$-ray counters.

\section{Description of Events}

\section{1. General}

The fifteen cases used in this study are listed in Table I with the appropriate Fig. num.

Table I

\begin{tabular}{|c|c|c|c|c|c|c|c|c|}
\hline \multirow{2}{*}{ Date } & \multirow{2}{*}{$\begin{array}{l}\text { Fig. } \\
\text { No. }\end{array}$} & \multicolumn{3}{|c|}{$\begin{array}{l}\text { Magnitude estimate } \\
\text { of maximum }\end{array}$} & \multicolumn{4}{|c|}{ Character figure for } \\
\hline & & $\begin{array}{c}X \\
(\text { cts } / \mathrm{sec})\end{array}$ & $\begin{array}{c}F \\
\text { (gamma) }\end{array}$ & $\begin{array}{c}M \\
\text { (gamma) }\end{array}$ & $F$ & $M$ & $I-S$ & $\theta$ \\
\hline \multicolumn{9}{|l|}{ Group I } \\
\hline $7 / 15 / 60$ & 2 & 100 & 750 & 16 & 0 & 2 & 5 & 3 \\
\hline $6 / 2 / 61$ & 3 & 160 & 500 & 7 & 3 & 6 & 5 & 6 \\
\hline $7 / 7-8 / 60$ & 4 & 17 & 395 & 2 & 1 & 3 & 5 & 5 \\
\hline $6 / 27 / 60$ & 5 & 21 & 130 & 3 & 2 & 5 & 4 & 3 \\
\hline $7 / 31 / 60$ & 6 & 12 & 700 & 5 & 2 & 2 & 4 & 6 \\
\hline $6 / 17 / 61$ & 7 & 250 & 200 & 3 & 1 & 5 & 3 & 6 \\
\hline \multicolumn{5}{|c|}{ Group Average } & 1.5 & 3.8 & 4.3 & 4.8 \\
\hline $\begin{array}{l}\text { Group II } \\
6 / 28 / 60\end{array}$ & $*$ & 19 & 1,700 & 7 & 4 & 6 & 5 & 5 \\
\hline $7 / 16 / 60$ & 8 & 55 & 1,100 & 17 & 4 & 6 & 4 & 4 \\
\hline $3 / 5 / 62$ & 9 & 6,500 & 1,500 & 8 & 6 & 6 & 3 & 4 \\
\hline \multicolumn{5}{|c|}{ Group Average } & 4.7 & 6.0 & 4.0 & 4.3 \\
\hline \multicolumn{9}{|l|}{ Group III } \\
\hline $7 / 30 / 60$ & 11 & 8 & 250 & 3 & 4 & 2 & 2 & 4 \\
\hline \multicolumn{5}{|c|}{ Group Average } & 4.0 & 2.0 & 2.0 & 3.5 \\
\hline \multicolumn{9}{|l|}{ Group IV } \\
\hline $8 / 1 / 60$ & 12 & 30 & 260 & 1 & 2 & 1 & 1 & 6 \\
\hline $6 / 18 / 61$ & 13 & 10 & 220 & 8 & 2 & 1 & 1 & 4 \\
\hline $6 / 22 / 61$ & 14 & 35 & 900 & 12 & 2 & 3 & 2 & 6 \\
\hline $6 / 24-25 / 61$ & 16 & 105 & 405 & 10 & 1 & 1 & 1 & 5 \\
\hline \multicolumn{5}{|c|}{ Group Average } & 1.8 & 1.5 & 1.2 & 5.3 \\
\hline \multirow{2}{*}{\multicolumn{5}{|c|}{$\begin{array}{l}\text { Average groups I to III } \\
\text { Average all data }\end{array}$}} & 2.8 & 4.2 & 3.8 & 4.5 \\
\hline & & & & & 2.5 & 3.4 & 3.1 & 4.7 \\
\hline
\end{tabular}

* (Campbell and Matsushita, 1962) 
bers. To describe the data, character figure were devised with values 0 to 6 where 2,4 and 6 refer to "fair", "good" and "excellent" relationship of the particle precipitation count rate, $X$, with increased micropulsation activity, $M$, with the growth in total variation field, $F$, or with a medium or large current magnitude, $I$, at a position, $S$ close to the station. The character figure assigned to $\theta$ indicates the degree to which an east-west electrojet is evident. The data were divided into four groups (Table I) indicative of the relationship of the line current and total field to the particle count rate. Four events whose $F$ and $I-S$ indices together were the lowest for the 15 balloon flights were placed in group IV. The remaining eleven events were separated into three character figure groups:

I high $I$-S and low $F$; evidence of a local line current whose position and magnitude may be successfully related to the intensity of particle bombardment.

II high $I-S$ and high $F$; the line current as well as the total field may be identified with the particle count rate.

III high $F$ and low $I$-S ; the particle flux is best related to the total field changes.

\section{2. The Events}

\section{July 15, 1960, Group I (Fig. 2)}

There is no information regarding the bremsstrahlung count rate before 1115 . The maximum in $X$ occurs close to a minimum in $F$ but during enhanced activity in $M$. Near the time of the peak count rate the current is of moderate size and overhead at the station ( $S$ goes to 0 and $\theta$ flips between north and south). For the second major peak particle flux, $F$ is rising as are $I$ and $M$ which reaches its second highest value of all events. $S$ is still rather small (about $150 \mathrm{~km}$ ) and considering the increased $I$, a fair relationship of the line current to the count rate is obtained. A westward electrojet ( $\theta$ in north or south when $H$ is negative) is indicated until about 1145 . The west to east position change near 1300 hours has no associated particle effects.

June 2, 1960, Group I (Fig. 3)

The total field shows three maxima, the first and last of which are at times of particle flux, $X$, peaks. The micropulsation amplitudes are large at times of high count rate. Looking at $S$ and $\theta$ it is seen that the overhead passings ( $S$ small and $\theta$ flips between $N$ and $S$ ) of the assumed line current occur when $I$ is of fair size and the particle precipitation is greatest. A good westward electrojet ( $\theta$ at $N$ or $S$ ) persists throughout the event.

July 7-8, 1960, Group I (Fig. 4)

The principal count rate $(X)$ peak occurs before the total field excursion maximum. The largest peak in $M$ occurs during the $X$ maximum and the preceding and two succeeding minima correspond. I is small and $S$ is rapidly varying from near to far away to near the station during this large $X$ maximum. The succeeding great field excursion near 0045 coincides with a large current at some distance from the station and no unique $X$-ray enhancement. The westward electrojet persists through most of the night; the apparent overhead passing near 2330 has little current associated with it.

June 27, 1960, Group I (Fig. 5)

The total field variation on this date is quiet small. Of the three major peaks in $F$ the second seems related to the $X$ maximum near 1320 . $M$ activity runs along well with $X$; note 


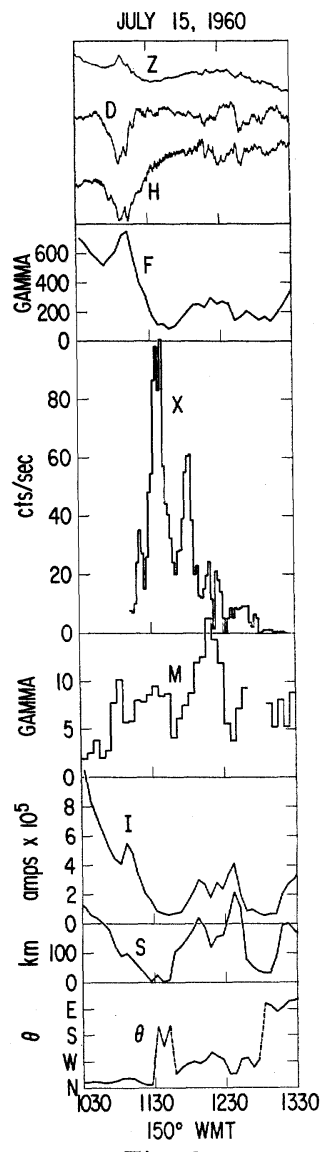

Fig. 2.

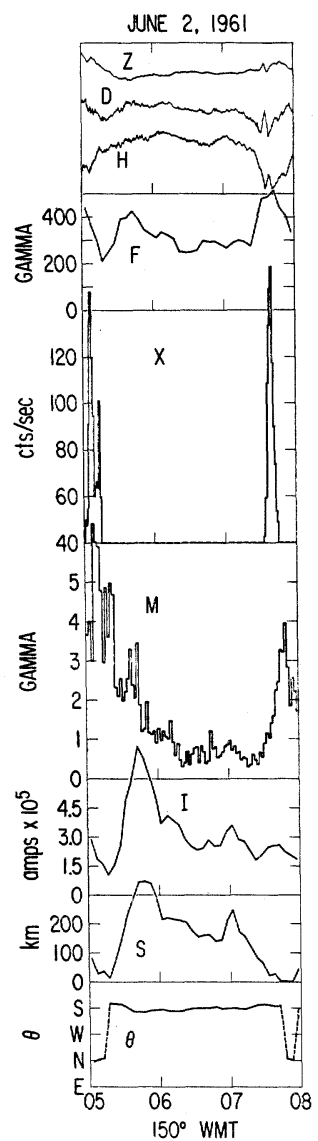

Fig. 3.

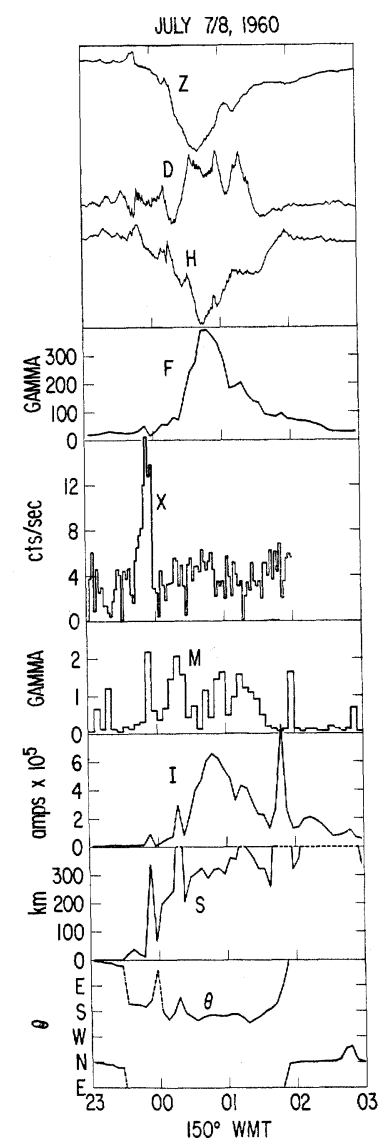

Fig. 4.

Fig. 2. The event of July 15,1960 . The seven graphs, from top to bottom, show the local magnetogram $(Z, D$, and $H)$, the total magnetic field variation above the quiet day value $(F)$, the brems strahlung $X$-ray count rate $(X)$, the peak to peak size of micropulsation amplitude $(M)$, the triangulated line current magnitude $(I)$, the surface projection of the closest approach distance of this line current to the observatory $(S)$, and the direction in which $S$ is measured in a geomagnetic coordinate system, $\theta$.

Fig. 3. The event of June 2, 1961. The interpretation of the graphs is the same as Fig. 2.

Fig. 4. The event of July $7 / 8,1960$. The interpretation of the graphs is the same as Fig. 2.

particularly the bursts near 1320,1440 , and 1500 . The line current is generally close to the station and overhead many times $(S=0)$ during the period of particle activity; the main $X$ peak occurs when $I$ is a fair size and about $100 \mathrm{~km}$ away. The $X$ activity near 1500 is when $I$ is large and $S$, though large, represents currents appearing alternately to the north and south of overhead ( $\theta$ flips between $N$ and $S$ ) and thus there may well be some overhead lectrojet. The $\theta$ variation for this event indicates an eastward current system (positive bay) from about 1215 to 1250 flowing generally south of the station. 


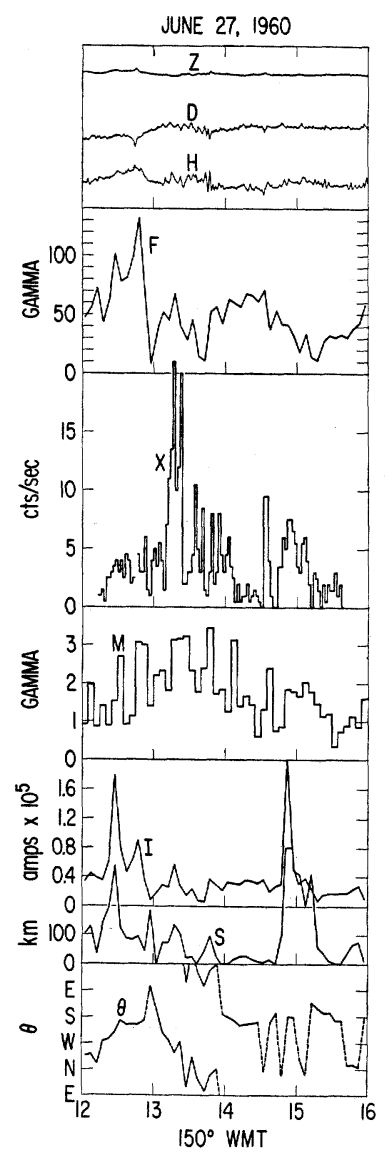

Fig. 5.

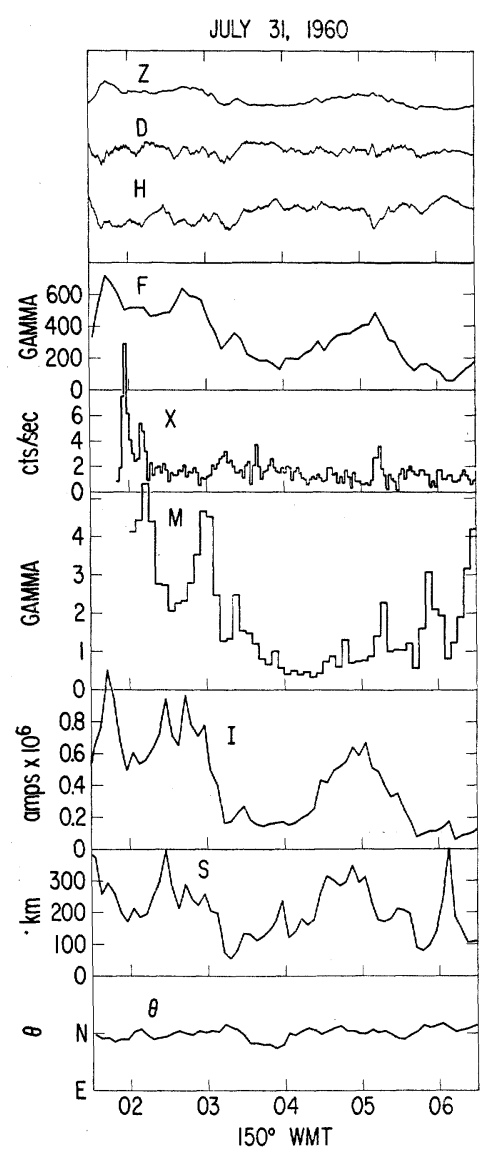

Fig. 6.

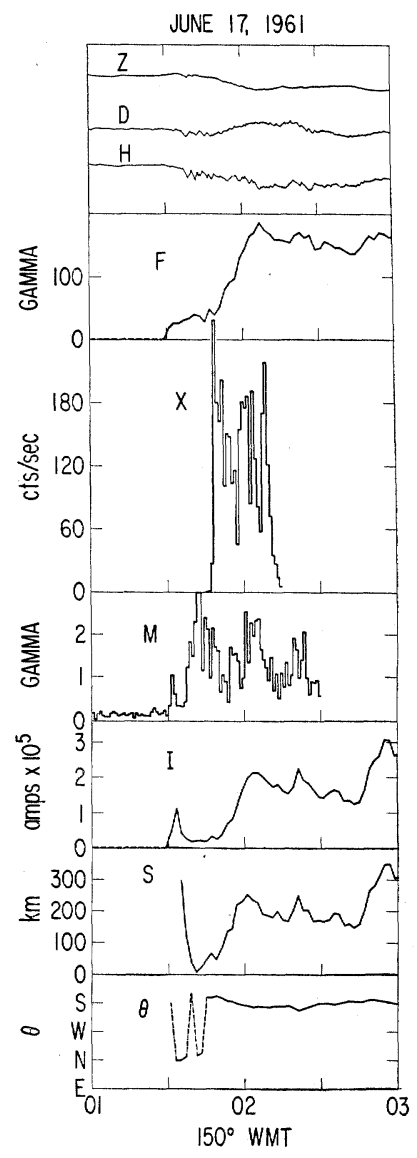

Fig. 7.

Fig. 5. The event of June 27, 1960. The interpretation of the graphs is the same as Fig. 2.

Fig. 6. The event of July 31, 1960. The interpretation of the graphs is the same as Fig. 2.

Fig. 7. The event of June 17, 1961. The interpretation of the graphs is the same as Fig. 2.

\section{Juily 31, 1961, Group I (Fig. 6)}

$F$ and $M$ are generally large during the $X$ activity but not uniquely identified with it. Particle flux peaks seem to occur at times of minima in $S$ and significant values of $I$. The westward electrojet is to the north of the station throughout the data period.

\section{June 17, 1961, Group I (Fig. 7)}

The disturbance field, $F$, is generally rising during the precipitation event but there is little correspondence beyond this. The micropulsation enhancement is of greater duration than that of $X$ but $M$ is better related to $X$ than $F$. The particle event starts at a time of rising $I$ while $S$ is small but then $X$ continues and ends with little relationship to the triangulated current. A westward electrojet appears overhead at the start of the enhanced electron precipitation and moves to a position about $200 \mathrm{~km}$ south of the station for the second hour of the observation. 
June 28, 1960, Group II (Campbell and Matsushita, 1962)

This event has the largest total field excursion. $F$ peaks are well related to particle flux maxima in time but not in size. The micropulsation enhancements also occur during the $X$ bursts and seem to be better related in relative amplitudes. The assumed line current, $I$, makes its closest approaches to the station (minima in $S$ ) at times of largest values of particle bombardment, $X$. A westward current flows during the event.

July 16, 1960, Group II (Fig. 8)

Although at the start of this event $F$ bears little relationship to $X$, the first two major peaks are clearly identified on both records; the last great enhancement in $F$ precedes that of $X$ by about one-half hour. $M$ runs along quite well with the bremsstrahlung count rate. The micropulsation maximum is the largest of all events. $I$ is also largest on this date. Close approaches of current near 0140 and 0700 to 0740 happen at the times of $X$ maxima; also the low $S$ values near $0235,0255,0430$ and 0520 may be identified with increased $X$. The $X$ peak at 0205 can be related to only a slight minimum in $S$ and peak in $1 . \theta$ indicates an electrojet which varies a bit in its general westward direction to the north of the station.

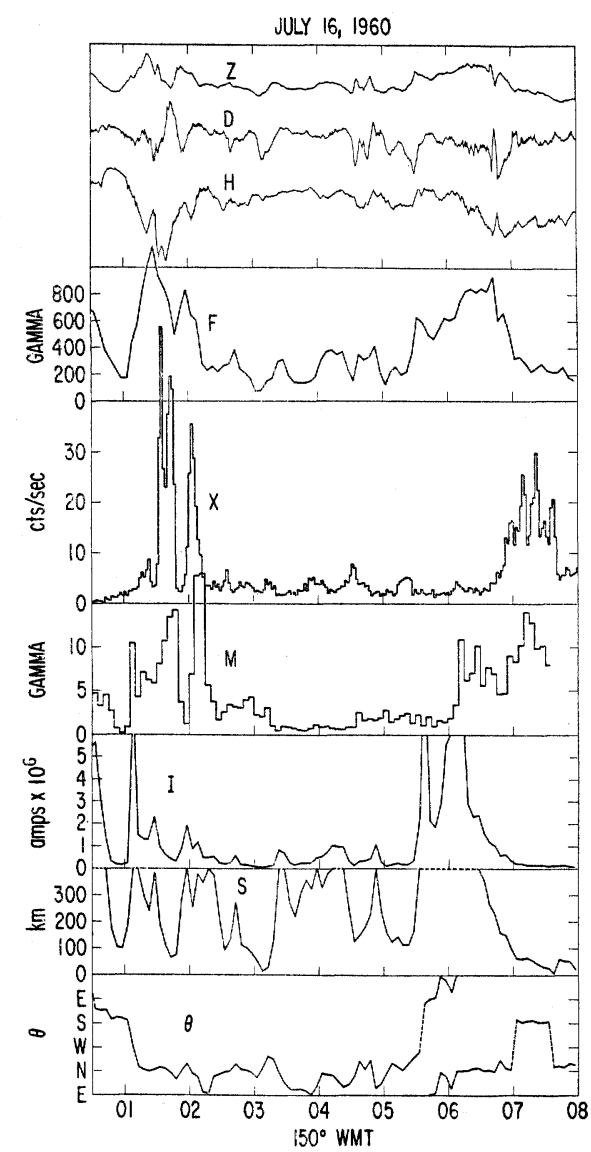

Fig. 8. The event of July 16,1960 . The interpretation of the graphs is the same as Fig. 2.

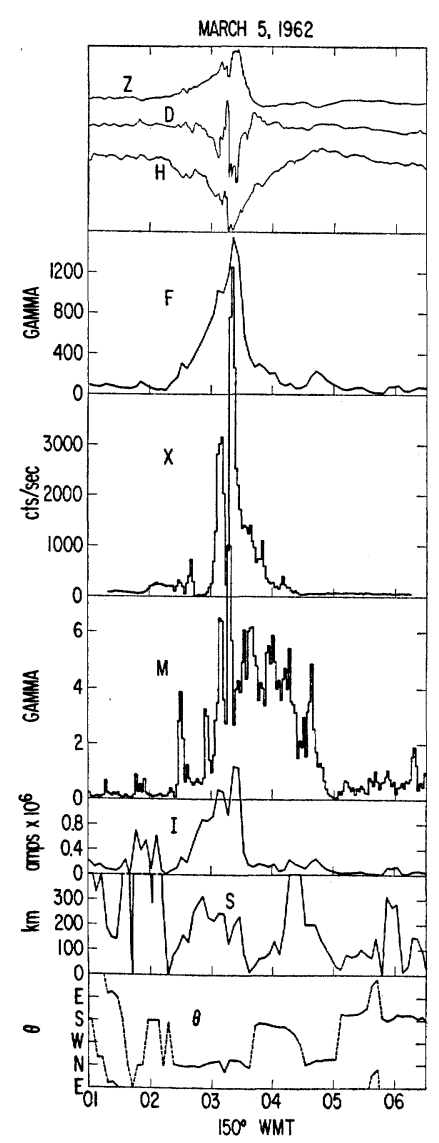

Fig. 9. The event of March 5, 1962. The interpretation of the graphs is the same as Fig. 2. 
March 5, 1962, Group II (Fig. 9)

This event has the highest count rate, third largest field excursion, and fourth largest triangulated current. The total field variation follows the particle precipitation quite well as do the micropulsations which show the two maxima seen in the count rate. The current

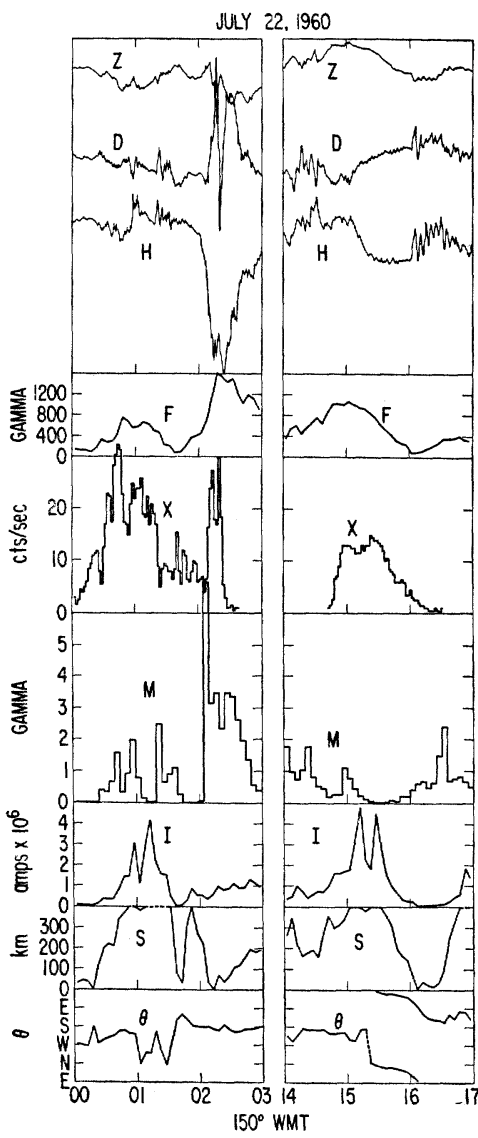

Fig. 10. The event of July 22, 1960. The interpretation of the graphs is the same as Fig. 2. system (I) is large and relatively close ( $S$ small) during the high count period and passes overhead $(\theta$ goes $N$ to $S$ ) shortly after the $X$ peak; the relationship is not at all exceptional. A clear westward electrojet flows throughout the high activity.

July 22, 1960, Group III (Fig. 10)

Two periods in which complete data were available are shown. $F$ and $I$ reach their second largest values on this date. One can see a good relationship of the total field with the count rate in the first hours of the event. $M$ generally follows $X$ in the early morning hours but only the 1500 peak may be jointly identified in the afternoon. when the balloon borne counters may have drifted considerably from the observing station. The close approaches of $I$ at 0020 , 0140 and 0215 as well as the overhead pass ( $\theta$ goes $S$ to $N$ ) near 0100,0120 and 0130 may be identified with $X$ enhancements but a relationship to the principal $X$ peak 0040 seems to be absent. The electrojet is westward through the major activity, is eastward from about 1400 to 1500 , and varies considerably in direction at other times.

July 30, 1960, Group III (Fig. 11)

The variations in $F$, although small, seem clearly identified with the particle flux. $M$ increases during the high count rate period and generally run along with $X$ except from 1100 to 1600 and 1730 to 1815 . The apparent overhead passage of current at 0920 and 1030 encourages the $I$-S relationship with $X$ as do the close approaches at 1647 at and 1730. However the data between 1100 and 1500 and near 1800 are not well correlated. A westward electrojet generally south of the station is established about 0830, breaks down about 1400 , and an eastward jet flows south of the station after 1600 . Note that particle precipitation is clearly associated with a positive bay-like event (eastward jet) in the early afternoon hours of this date.

\section{August 1, 1960, Group IV (Fig. 12)}

The four events of Group IV showed the poorest average relationship of count rate to the total field, $F$, and current-position $(I-S)$. A few interesting points should be noted, On the August 1 event a westward electrojet soute of the station seems to twist around gradu- 


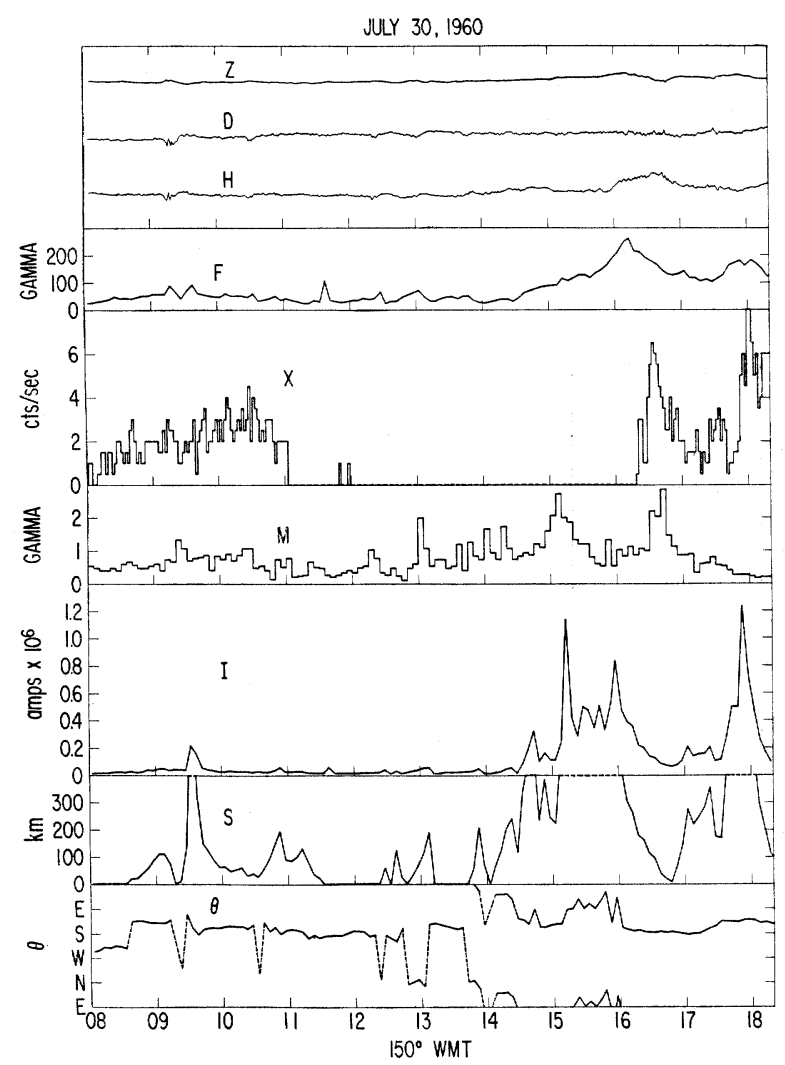

Fig. 11. The event of July 30, 1960. The interpretation of the graphs is the same as Fig. 2.

ally, in the west, to a north position at which time there appears a jump to the south of the station and the establishment of an eastward electrojet. Note that the precipitation is during this positive bay following its maximum excursion.

June 18, 1961, Group IV (Fig. 13)

This event shows a general relationship of all data for only the first hour and a half, at a time before the westward electrojet is clearly established.

June 22, Group IV (Fig. 14)

From 0000 to 0530 the variations in $F$ and $M$ as well as the near approach (low $S$ ) of electrojet current, $I$, would place this event in Group II. However, the count rate quiet periods and bursts during the remaining six hours may be only slightly identified with the other data. The westward electrojet is clearly evident throughout the night. As a typical but not outstanding example of the triangulation, Fig. 15 shows the surface projection of the apparent intercept position of the vector, $S$, from College perpendicular to a linear current, $I$, at $100 \mathrm{~km}$ for the duration of the maximum bremsstrahlung count rate from 0001 to 0101 in two minute intervals. Note the close approaches of the line current to the station at 0007 to 0009,0027 and 0101 . Of these times the largest current (Fig. 14 shows about 0.5 $\times 10^{6}$ amperes) flows at 0027 . This is the time of maximum particle preciptation. The total 


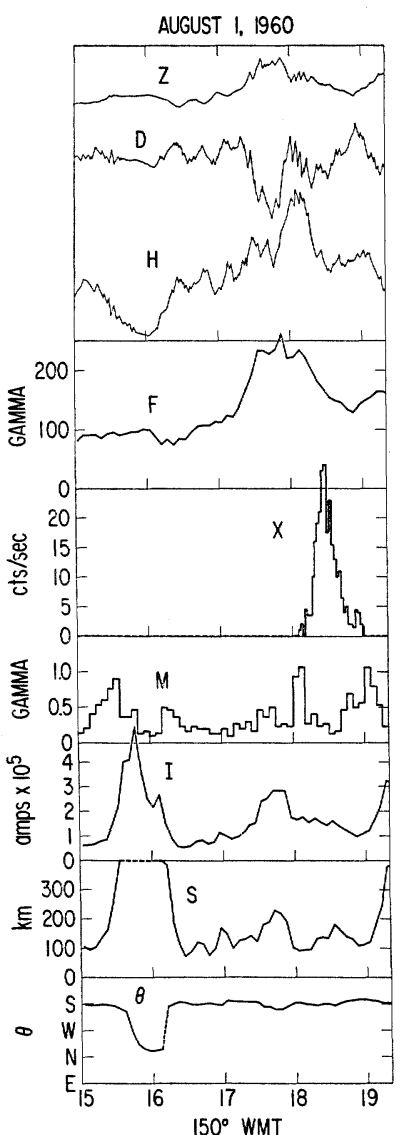

Fig. 12. The event of August 1, 1960. The interpretation of the graphs is the same as

Fig. 2.

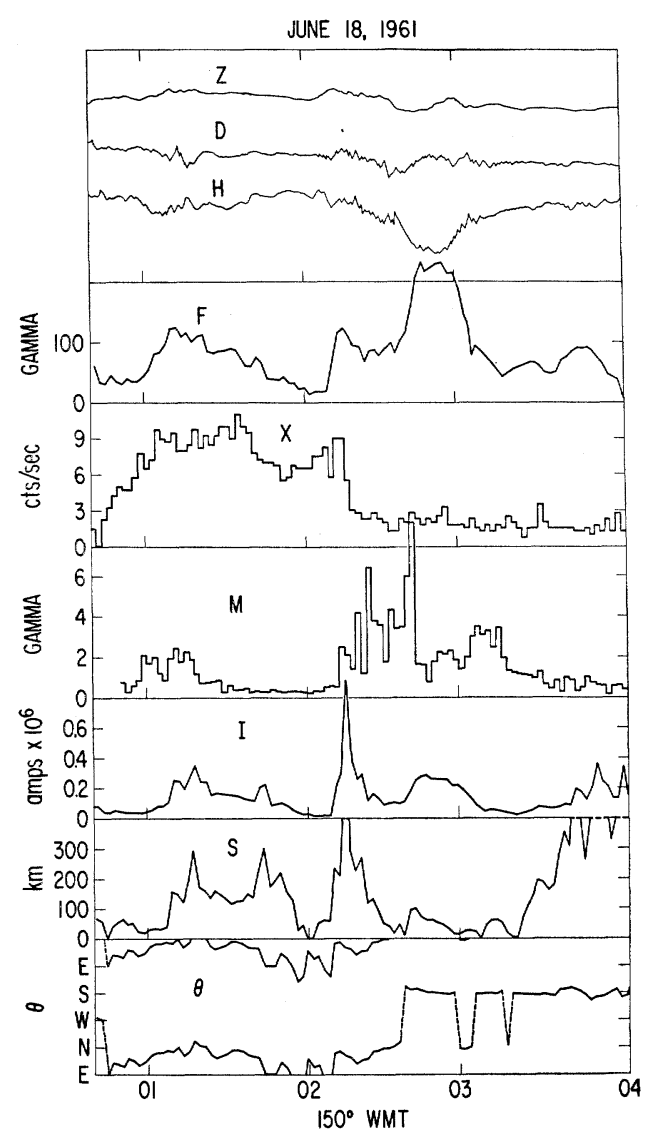

Fig. 13. The event of June 18, 1961. The interpretation of the graphs is the same as Fig. 2.

field excursion maximizes about eight minutes later.

June 24-25, 1961, Group IV (Fig. 16)

The maximum particle flux happens during the first overhead passage of the line current ( $\theta$ goes $N$ to $S$ ) when the westward electrojet has just been established. However, the subsequent changes are not as easily interpreted. $X$-ray count rates preceding and following the maximum are not well related to $F, M$, or $I-S$. Fine structure in the particle precipitation maximum is illustrated in Fig. 17 (from Brown and Campbell, 1962). Many of the micropulsation pulses here may be identified with the electron bursts (A through $M$ ); note particularly $K$ and $L$ during the peak of activity. A frequency dependent phase shift, unfortunately present in the magnetic field sensors, obscures a clear relationship between the two phenomena. 


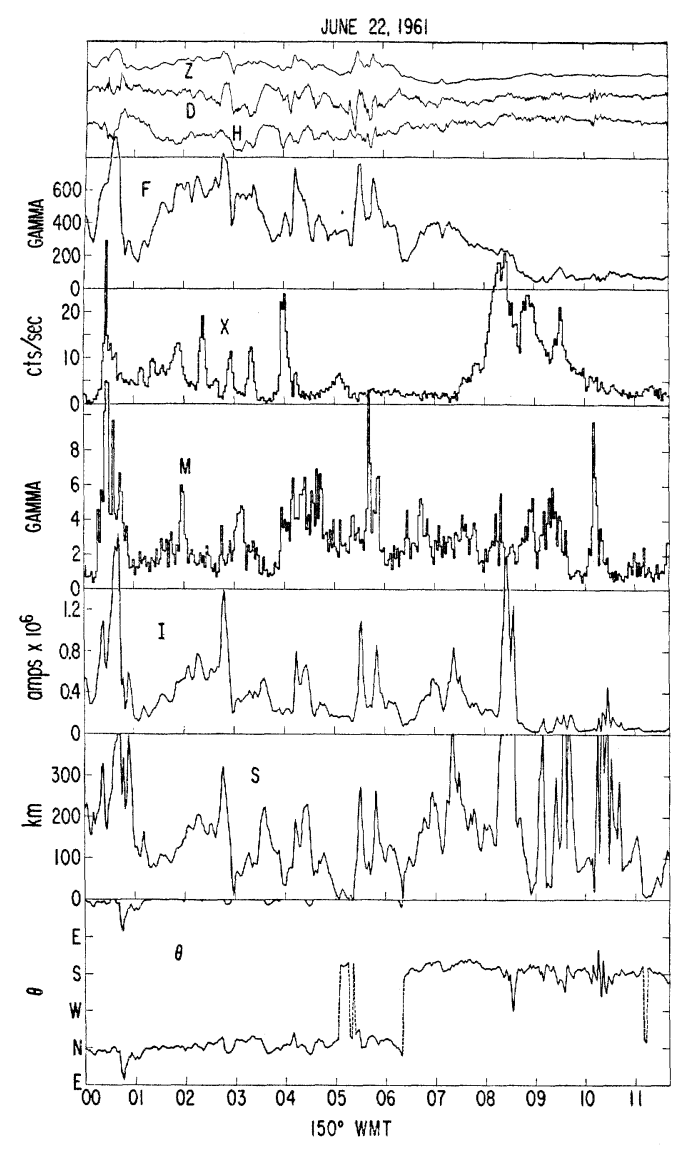

Fig. 14. The event of June 22, 1961. The interpretation of the graphs is the same as Fig. 2.

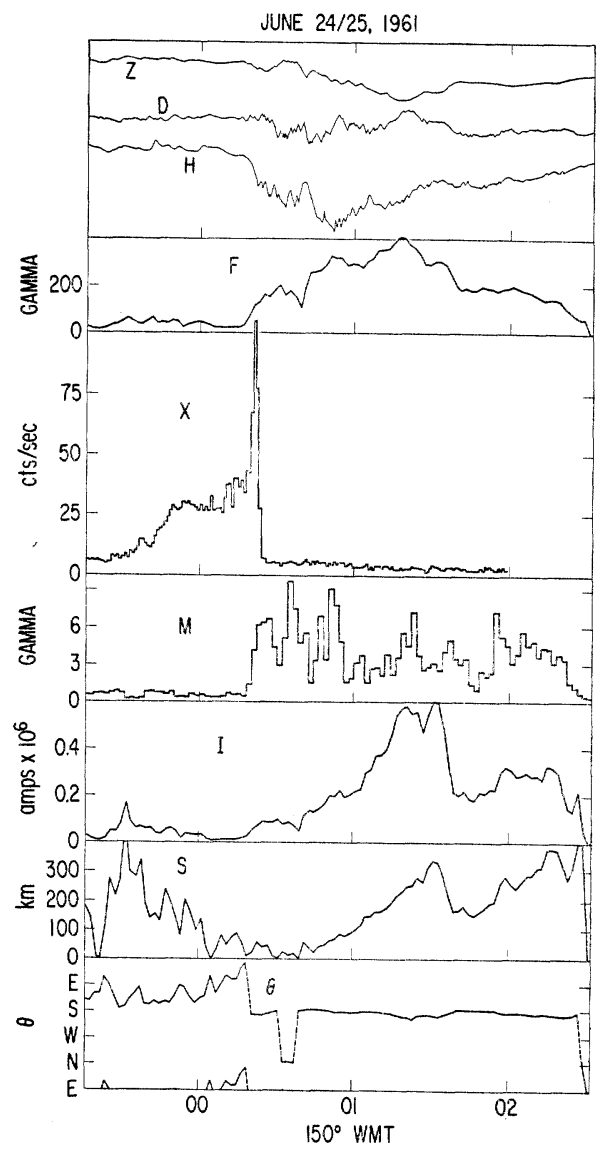

Fig. 16. The event of June $24 / 25$, 1961. The interpretation of the graphs is the same as Fig. 2.

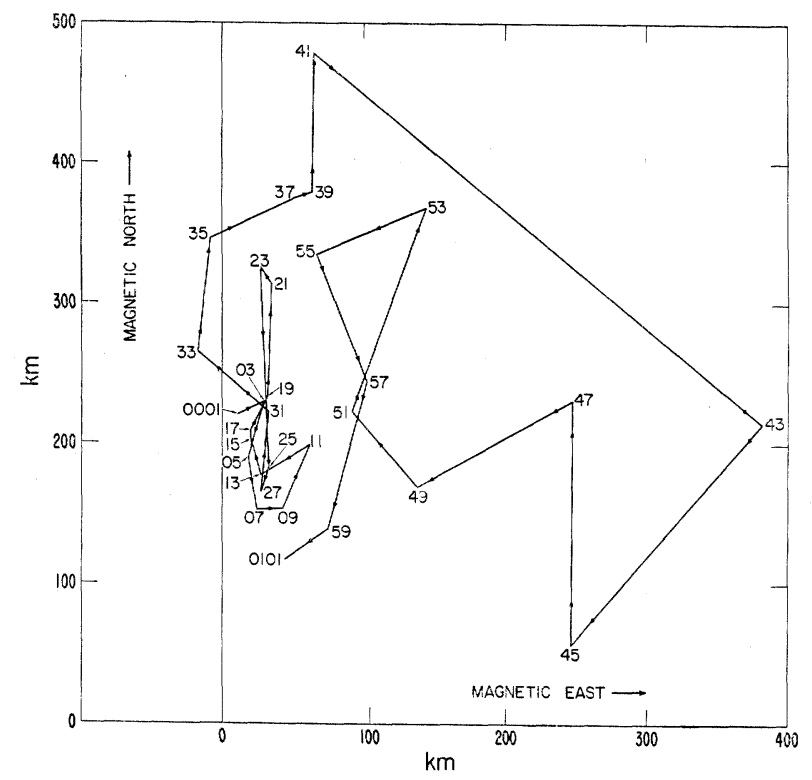

Fig. 15. The surface projection of the appearent intercept position of the vector, $S$, from College perpendicular to a linear current, $I$, at $100 \mathrm{~km}$ for the event of June 22, 1961, for two minute intervals from 0001 to 0101 hours $150^{\circ}$ 


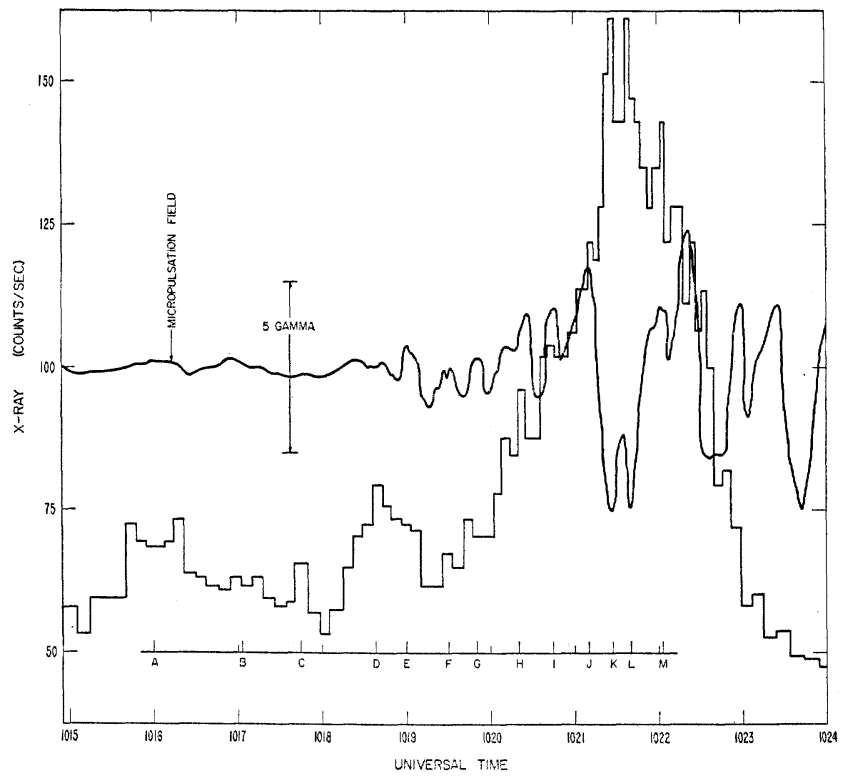

Fig. 17. Fine structure in bremsstrahlung count rate and geomagnetic micropulsation field during a peak of activity in the June 24/25, 1961, event of Fig. 16. Of the interesting points of correlation A through $M, K$ and $L$ are quite striking.

\section{Discussion}

The discussion will first center upon the Table I resume of data. From the estimation of magnitude for the maximum activity of each event several things are evident. There is just a slight relationship of the field strength maxima of $M$ with $F$. There is some tendency of both these magnitudes to be larger at times of high bremsstrahlung count rate only when the several largest $X$ maxima are excluded. Days when the triangulated current could be related to the particle flux were usually days of high peak count rate. In general, the magnitudes of the maxima in the three parameters, $X, F$ and $M$, for each event were not good indicators of a relationship between the geomagnetic effects and the electron precipitation.

The high character figure of $\theta$ show that an east-west electrojet is usually flowing regardless of the level of particle or field activity.

The four data groups were determined on the basis of the relationship of the character figure of $F$ and $I$-S to $X$. An attempt will be made to interpret them in such a way that the ionospheric electrojet and precipitation regions are assumed identical. Composing Group I are cases in which a line current triangulation from the magnetic field data leads to a relationship between the near approach of an electrojet current and a high electron count rate.

Group II events are interpreted to be cases in which the variation in precipitation is related over a rather large area. Broad sheet or multiple line currents seem to be flowing in the ionosphere; triangulation on the large nearby currents aids in the interpretation of the data. The only winter flight of this study, on March 3, falls into Group II. The all-sky 
camera photos of the aurora during this event (Anderson and DeWitt, 1963) certainly indicate both multiple arcs and widespread glow.

We construe Group III to be events in which the precipitation is spread over a broad area and that randomly enhanced multiple sheet or line currents are flowing. Although such random variations confuse the triangulation method they still relate the flux to the total field variation. Note that $\theta$, the indicator of a clearly defined electrojet, has a low average value for this group.

The last four events (Group IV), although selected for lowest $F$ and $I$-S character figure also show the lowest average relationship of count rate with micropulsation amplitudes, $M$. In section 2 above there was presented some of the problems accompanying and attempted straightforward data interpretation; it is possible that these are significant in Group IV. Nevertheless, note that in Fig. 13, the character figure for $F$ would be large at the beginning of the event; in Fig. 14, $M, F$ and $I-S$ character figure would be large in the early hours of the day, and in Fig. 16, $M$ and $I-S$ show clear relationships to the peak of count rate activity.

The character figure averages in Table I imply that micropulsation amplitudes and the triangulated electrojet line currents are good geomagnetic indices of particle flux; where as the total field by itself is only a fair indicator. It does seem, however, that $F$ and $I \cdot S$ are complementary and, taken together, provide a better interpretation of the precipitation region.

Marsh (1963) observed that the usual triangulation often shows an apparently unreal growth of the current as the system moves away from the station. He suggested that this effect is a result of an improper allowance for the induced current giving an overestimation of the distance to the electrojet. The situation clearly arises in many of the 15 events of this paper but rather drastic revision of the induced current factors would be necessary to appreciably modify the calculated current growth. It seems, rather, that the problem lies with the assumption of a single line current. At a distance, $r$, from an infinitely long, line current the measured magnetic field varies as $r^{-1}$. For a complicated, multiple element or broad sheet electrojet the observed field probably varies as $r^{-n}$ with $1 \supseteq n \geqslant 0$ which would account for some of the erroneous, computed growth of the current with increasing distance from the station.

The events showed a consistent east-west current system which would indicate that there is generally little difference in using $H$ instead of $F$ as a total field disturbance indicator at the station. At College, Alaska, geomagnetic and magnetic north closely coincide. The geomagnetic east-west auroral arcs and electrojet systems there show up well on variations of the magnetic north component of the surface field $(\Delta H)$. In other regions of the auroral zones, the arcs and jets may be at considerable angle to magnetic east-west; in such cases the variations in the eastward component of the horizontal field $(\Delta D)$ become important.

Although there were merely 15 events sampled some general features of the electrojet appeared. In the local hours of 0000 to 0600 the westward electrojets (negative bays) to the north of the station predominated; from 0600 to 1200 the westward electrojets were to the south. The eastward electrojets (positive bays) prevailed to the south of Callege from about 
1200 to 1900 . In the transition times of the early post-midnight and noon hours the jet triangulation often seemed confused. This general behavior should probably be expected from a station rotating under the high latitude storm-like daily variation, $S_{D}$, current system (c.f. Vestine, 1960) or under the statitical pattern of auroral arc alirgnment (c.f. Davis 1962).

Although there was a slight indication of a preference for maxima in bremsstrahlung count rate during the large, post-midnight negative bays (westward electrojets), the four data groups were spread throughout the day. Of the positive bay-like events (eastward electrojets), in Fig. 5 from 1200 to 1300, Fig. 10 from 1400 to 1500, Fig. 11 from 1600 to 1700, and Fig. 12 from 1700 to 1900 , the last two were associated with particle preceipication. The observation of tnese two events encourages two conclusions: that mirror height lowering due to decreased field $(-\Delta H)$ is not a necessary condition for the precipitation and that the sense of the driving electric field for the elctrojet is not depent upon the arriving particles. Nevertheless, without this driving electric field no current will flow regardless of the extent of conductivity enhancement by the new ioinzation. Therefore, there are times when we expect precipitation without appreciable magnetometer variations.

The high character figure for the relationship between the micropulsation activity and $X$-ray count rate shown in Table I as well as the identical small scale variations in amplitudes lead one to the conclusion that the geomagnetic micropulsations are good indicators of auroral zone electron precipitation. The data are consistent with the proposal that small changes of ionospheric conductivity brought about by the particle bombardment give rise to small, local electrojet fluctuations. Considering the driving electric field $(E)$ and the gyro- $(\omega)$ and collision- $(\nu)$ frequency of particles within the conducting region to be changing slowly with respect to the field pulsations, the fractional change in current density $(j)$ would be directly proportional to the fractional change in the conductivity $(\sigma)$. The former may be obtained from the fractional change in total field $(B)$ and the latter from the fractional change in electron density $\left(n_{e}\right)$. That is

$$
j=\sigma \cdot E,
$$

where $\sigma$ is the tensor layer conductivity. In the auroral zone with the earth's total field almost perpendicular to the earth's surface

$$
\sigma=\left[\begin{array}{r}
\sigma_{1} \sigma_{2} \\
-\sigma_{2} \sigma_{1}
\end{array}\right]
$$

where $\sigma_{1}$ is the transverse (Pedersen) conductivity,

$$
\sigma_{1}=\mathrm{n}_{e} e^{2}\left[\frac{\nu_{e}}{m_{e}\left(\omega^{2}{ }_{e}+\nu^{2}\right)}+\frac{\nu_{i}}{m_{i}\left(\omega^{2}+\nu_{i}^{2}\right)}\right]
$$

and $\sigma_{2}$ is the Hall conductivity,

$$
\sigma_{2}=n_{e} e^{2}\left[\frac{\omega_{e}}{m_{e}\left(\omega^{2}{ }_{e}+\nu^{2}\right)}-\frac{\omega_{i}}{m_{i}\left(\omega_{e}^{2}+\nu^{2}\right)}\right] .
$$

Subscripts $e$ and $i$ refer to electrons and ions respectively. Thus, the eastward (y) component of the current density is given by 


$$
j_{y}=-\sigma_{2} E_{x}+\sigma_{1} E_{y} .
$$

For constant or slowly changing $E, \omega, \nu, e$, and $m$ in the electrojet

$$
\frac{d j_{y}}{j_{y}} \approx \frac{d n_{e}}{n_{e}}
$$

Now $j$ is proportional to the field strength. Assuming, from Table I, average $M$ and $F$ magnitudes of 7 and 700 gamma we obtain $d j_{y} / j_{y} \approx 10^{-2}$. This implies that a mere increase of one per cent in the electron density can give the required perturbation of the electrojet necessary for micropusations.

The enhanced ionospheric electron density, $n_{e}$, which results from the auroral zone particle bombardment, has been estimated from the First Negative emission system of the excited, singly ionized, molecular nitrogen in the aurora (e.g. Bates, 1960);

$$
n_{e}=[K P(\text { lst Neg }) / \boldsymbol{\alpha}]^{\frac{1}{2}}
$$

where $K$ is a constant, $P(1$ st Neg) is the photon emission rate and $\alpha$ is the effective recombination coefficient. Observations of this emission in the geomagnetic micropulsation frequencies (Campbell and Rees, 1961) indicated the rapid variations to be an average $5 \%$ and occasionally greater than $20 \%$ of total luminosity. This, then, corresponds to rapid electron density fluctuations of $2 \frac{1}{2}$ and $10 \%$, certainly of sufficient size to cause geomagnetic pulsations of the electrojet.

\section{Concluding Remarks}

Past studies of some unique auroral events have demonstrated a special relationship between the triangulated position of the electrojet, the point of electron precipitation, and the region of high electron density. These reports were for selected events. One wonders whether such a clear interdependence holds for the typical observation. In this paper a general view of what may be expected from the magnetic effects at times of auroral zone bremsstrahlung $X$-ray events has been presented. Notwithstanding the many problems in obtaining a clear interpretation of the data there was evident an association of the count rate to the negative and positive bays as well as the storm type geomagnetic micropulsations. In a number of cases the magnitude and position of the triangulated electrojet seemed to be uniquely related to the size and location of the inferred electron precipitation. This encouraged an attempt to explain the remaining cases in terms of the size and location of the region beging bombarded by the electrons. Inherent problems, particularly in the balloon method of observation and the line electrojet idealization which were discussed at the onset, made the accurate data interpretation difficult. More winter balloon fiights supported by all sky auroral photographs are needed to determine whether the resolution of total field and the electrojet may be used effectively to describe the precipitation region for the majority of events.

It still seems evident that the micropulsations and irregular fluctuations in auroral zone bays have their source in the ionization created by the particle precipitation. The instantaneous size and direction of the auroral ionospheric current systems (Fukushima, 1953) 
depend upon both the driving electric field, $E$ and the newly created ionization. We would suspect that the latter accounts for a major part of the irregular disturbance variation, $D_{i}$, as was implied by Nikolski (1947), whereas processes for the slower variation in $E$ arise in the outer reaches of the magnetosphere (c.f., Axford and Hines, 1961; Kern 1962; Swift, 1963).

The balloon data was graciously supplied by Dr. Robert R. Brown, Dr. Kinsey Anderson, Dr. David Evans, Dr. Clifford Anger, and Dr. David Marsh, all of the University of California. The author would like to thank the Geophysical Institute of the University of Alaska for its assistance in carrying out the observations. The scaling and computer programs for triangulation were done by Miss A.F. Moser and Mr. E. Stiltner of the National Bureau of Standards.

\section{References}

Akasofu, S.I., "Large-Scale Auroral Motions and Polar Magnetic Disturbances, I.," J. Atmos. \& Terr. Phys., Vol. 19, 1960, pp. 10-25.

Anderson, K.A., "Soft Radiation Events at High Altitude During the Magnetic Storm of August 29-30, 1957," Phys. Rev., Vol. 111, 1958, pp. 1397-1405.

Anderson, K.A., "Balloon Observations of $X$-Rays in the Auroral Zone, 1," J. Geophys. Res., Vol. 65, 1960, pp. 551-564.

Anderson, K.A. and D.C. Enemark, "Balloon Observations of $X$-Rays in the Auroral Zone, 2," J. Geophys. Res., Vol. 65, 1960, pp. 3521-3538.

Anderson, K.A. and R. DeWitt, "Space-Time Association of Auroral Glow and X-Rays at Balloon Altitude,” J. Geophys. Res., Vol. 68, 1963, pp. 2669-2675.

Anger, C.D., J.R. Barcus, R.R. Brown, and D.S. Evans, "Auroral $X$-Ray Pulsations in the 1-15 Second Period Range,” J. Geophys. Res., Vol. 68, 1963, pp. 1023-1030.

Axford, W.I. and C.O. Hines, "A Unifying Theory of High-Latitude Geophysical Phenomena and Geomagnetic Storms," Can. J. Phys., Vol. 39, 1961, p. 1433.

Baker, W.G. and D.F. Martyn, "Electrical Currents in the Ionosphere, I. The Conductivity," Phil. Trans. Roy. Soc., A, 246, 1963, pp. 281-294.

Bates, D.R., "The Auroral Spectrum and Its Interpretation," Physics of the Upper Atmosphere, J.A. Ratcliffe, Ed., 1960, New York and London, Academic Press, p. 337.

Barcus, J.R. and R.R. Brown, "Electron Precipitation Accompanying Ionospheric Current Systems in the Auroral Zone," J. Geophys. Res., Vol. 67, 1962, pp. 2673-2681.

Brown, R.R., "Balloon Observations of Auroral Zone X-Rays," J. Geophys. Res., Vol. 66, 1961, pp. 13791388.

Brown, R.R., "A Comparison of Auroral Zone $X$-Ray Observations from Periods with Different Levels of Solar Activity," J. Geophys. Res., Vol. 67, 1962, pp. 2681-2684.

Brown, R.R., et al, "Large-Scale Electron Bombardment of the Atmosphere at the Sudden Commencement of a Geomagnetic Storm," J. Geophys. Res., Vol. 66, 1961, pp. 1035-1042.

Brown. R.R. and W.H. Campbell, "An Auroral Zone Electron Precipitation Event and Its Relationship to a Magnetic Bay," J. Geophys. Res., Vol. 67, 1962, pp. 1357-1366.

Burritt, E.H., Geography of the Heavens and Classbook of Astronomy, New York, Hunnington and Savage Co., 1845, pp. 291-292.

Campbell, W.H., "Magnetic Micropulsations and Electron Bremsstrahlung," J. Geophys. Res., Vol. 66, 1961, pp. 3599-3600. 
Campbell, W.H., "Some Auroral Zone Disturbances at Times of Magnetic Micropulsation Storms," paper I-2-14 presented at International Conference on Cosmic Rays and Earth Storm, Kyoto, Japan, Sept 1961). J. Phys. Soc. Japan, Vol. 17, Suppl. A-1, 1962a, pp. 112-116.

Campbell, W.H., "Concerning an Ionospheric Current System Theory of Geomagnetic Micropulsations" (paper 18 presented at American Geophysical Union Meeting, Geomagnetism and Aeronomy Section, Washington, D.C., Apr 1962b, pp. 1-5.

Campbell, W.H. and H. Leinbach, "Ionospheric Absorption at Times of Auroral and Magnetic Pulsations," J. Geophys. Res., Vol. 66, 1961, pp. 25-34.

Campbell, W.H. and M.H. Ress, "A Study of Auroral Coruscations," J. Geophys. Res., Vol. 66, 1961, pp. 41-55.

Campbell, W.H. and S. Matsushita, "Auroral-Zone Geomagnetic Micropulsations with Periods of 5 to 30 Seconds,” J. Geophys. Res., Vol. 67, 1962, pp. 555-573.

Chapman, S., "The Electric Current Systems of Magnetic Storms," Terr. Mag. Atmos. Elect., Vol. 40, 1935, pp. 349-370.

Chapman, S., "The Electrical Conductivity of the Ionosphere: A Review," Nuovo cimento, Vol. 4 (suppl.), 1956a, pp. 1385-1412.

Chapman, S., "The Morphology of Geomagnetic Storms and Bays: A General Review," Vistas in Astronomy, Vol. 2, A. Beer, Ed., 1956b, London and New York, Pergamon Press, pp. 912-928.

Chapman, S. and T.T. Whitehead, "The Influence of Electrically Conducting Material Within the Earth on Various Phenomena of Terrestrial Magnetism," Trans. Camb. Phil. Soc., Vol. 22, 1923, pp. 463-482.

Davis, L.R., O.E. Berg, and L.H. Meredith, "Direct Measurements of Particle Fluxes in and Near Auroras," Space Research, H. Kallmann, ed., North Holland Pub. Co., 1960, pp. 721-735.

Davis, T.N., "The Morphology of the Auroral Displays of 1957-1958, 2," J. Geophys. Res., Vol. 67, 1962, pp. $75-110$.

Evans, D.S., “A Pulsating Auroral-Zone $X$-Ray Event in the 100 Sec. Period Range," J. Geophys. Res., Vol. 68, 1963, pp. 395-400.

Fukushima, N., "Polar Magnetic Storms and Geomagnetic Bays," J. Fac. Sci. Univ. Tokyo, Vol. 8, Sect. II, 1953, p. 293.

Kern, J.W., "A Charge Separation Mechanism for the Production of Polar Auroras and Electrojets," J. Geophys. Res., Vol. 67, 1962, pp. 2649-2665.

Maehlum, B. and B.J. O'Brien, "Study of Energetic Electrons and Their Relationship to Auroral Absorption of Radio Waves,” J. Geophys. Res., Vol. 68, 1963, pp. 997-1010.

Marsh, D.P., "Observations Relating to the Distance-Scale for Motions of Elestrojet-Electron Precipitation Regions in the Auroral Zone," J. Geophys. Res., Vol. 68, 1963, pp. 4167-4174.

Matsushita, S., "Increase of Ionization Associated with Geomagnetic Sudden Commencements," J. Geophys. Res., Vol. 66, 1961, pp. 3958-3961.

Matsushita, S., "On Geomagnetic Sudden Commencements, Sudden Impulses, and Storm Durations," J. Geophys. Res., Vol. 67, 1962, pp. 3753-3777.

McIlwain, C.E., "Direct Measurement of Particles Producing Visible Auroras," J. Geophys. Res., Vol. 65,1960 , pp. 2727-2748.

Nikolski, A.P., "Dual Laws of the Course of Magnetic Disturbances and the Nature of Mean Regular Variations," Terr. Mag. Atmos. Elect., Vol. 52, 1947, pp. 147-173.

O'Brien, B.J. and C.D. Laughlin, “An Extremely Intense Electron Flux at $1000 \mathrm{~km}$ Altitude in the Auroral Zone," J. Geophys. Res., Vol. 67, 1962, pp. 2667-2672.

Omholt, A., "Studies on the Excitation of Aurora Borealis," Geophys. Pub., Vol. 20, 1959, pp. 1-40. 
Pfotzer, G., et al, "A Contribution to the Morphology of $X$-Ray Bursts in the Auroral Zone," J. Geophys. Res., Vol. 67, 1962, pp. 575-585.

Swift, D.W., Electric Fields and Current Flows in an Auroral Arc, RAD-TR-63-14, AVCO Corporation, 1963, pp. 1-43.

Terada, T., "On Rapid Periodic Variations of Terrestrial Magnetism," J. of College of Sci., Imperial Univ. of Tokyo, Vol. XXVII, Article 9, 1917.

Troitskaya, V.A., "Pulsations of the Earth's Electromagnetic Field with Periods of 1 to 15 Seconds and Their Connection with Phenomena in the High Atmosphere," J. Geophys. Res., Vol. 66, 1961, pp. 5-18.

Vestine, E.H., "The Upper Atmosphere and Geomagnetism," Physics of the Upper Atmosphere, J.A. Ratcliffe, Ed., 1960, New York and London, Academic Press, pp. 498-503.

Winckler, J.R., et al, “ $X$-Rays from Visible Auroral at Minneapolis," Phys. Rev., Vol. 110, 1958, pp. 1221-1231.

Winckler, J.R., et al, "Auroral $X$-Rays, Cosmic Rays and Related Phenomena During the Storm of February 10/11, 1958," J. Geophys. Res., Vol. 64, 1959, pp. 597-610.

Winckler, J.R., P.D. Bhavsar, and K.A. Anderson, "A Study of the Precipitation of Energetic Electrons from the Geomagnetic Field During Magnetic Storms,” J. Geophys. Res., Vol. 67, 1962, pp. 3717-3736. 